\title{
The Paranoid Style and the Rise of Fake News in American Politics
}

\author{
Peter L. Francia, Professor \\ Director, ECU Center for Survey Research \\ Department of Political Science \\ East Carolina University \\ Greenville, NC 27858 \\ franciap@ecu.edu
}

\begin{abstract}
In 1964, historian Richard Hofstadter authored the seminal text, The Paranoid Style in American Politics. Fifty-five years later in an era now littered with "fake news" websites and conspiracy theories that can spread rapidly over the Internet, Hofstadter's investigation into "the politics of the irrational" warrants revisiting. In this paper, I draw on the concept of the "paranoid style" originally developed by Hofstadter, but with a quantitative twist. Psychologists Allan Fenigstein and Peter Vanable (1992) developed a now widely used survey instrument to assess paranoid thought. Using data from an original nationwide and demographically representative survey of more than 800 adults that combines the Fenigstein and Vanable paranoia instrument with questions about popular present-day political conspiracies and well-publicized fake news stories, my research asks the question: Is there a relationship between paranoia and one's willingness to accept or deny established political facts? Drawing on Hofstadter's earlier work about the "paranoid style," I hypothesize that in today's sometimes confusing information environment, which includes both credible and fake news, paranoia plays a significant role in understanding why some Americans are more susceptible than others to believing misinformation popularized through fake news websites. The results of this research confirm my expectations and raise potentially serious implications for democratic theory, which holds that an informed citizenry is necessary for elections and government to function properly. By examining the theory of the "paranoid style" in today's modern context, this research offers potentially useful insights into better understanding why some people are better able to differentiate facts from fiction in the political arena. These results have clear and obvious implications for the future of American democracy.
\end{abstract}

Paper prepared for presentation at the annual meeting of the American Political Science Association, Washington, DC, August 29-September 1, 2019.

Please direct all correspondence to Peter L. Francia at the contact information above. The author gratefully acknowledges the Thomas Harriot College of Arts and Sciences at East Carolina University for the services and infrastructure support that it provides to the Center for Survey Research. The author also wishes to thank Toby Board and Randy Knebel of the ECU Center for Survey Research for their invaluable research and technical assistance on this study. 
On March 26, 2017, the television program, 60 Minutes, investigated the rise of so-called "fake news" in American politics. As the 60 Minutes segment detailed, demonstratively false stories promulgated via fake news websites, such as the National Report and Denver Guardian, have become an increasing, and to many observers, including former President Barack Obama, an alarming part of contemporary American politics and discourse (see e.g., Korte 2016). In July of 2016, for example, a fake news website, wtoe5news.com, falsely reported that Pope Francis had endorsed Donald Trump for president - a story that Facebook users shared more than one million times (Allcott and Gentzkow 2017). In another well-publicized example of fake news, a North Carolina man, who believed a patently false story that Hillary Clinton and her aides were running a child sex operation from a Washington, D.C. pizzeria, drove to the nation's capital and fired a gun in the restaurant. Even though there were no injuries, the seriousness of the matter brought increased attention to the consequences of fake news for American democracy and society.

The dissemination of misinformation and rumors is certainly not new to the American political landscape, nor is it new for there to be a receptive audience willing to believe virtually any far-fetched political conspiracy. Indeed, the historian Richard Hofstadter, in his classic book, The Paranoid Style in American Politics, documents how Americans, since the founding of the republic, have been prone to believing any number of bizarre, irrational, and often paranoid fantasies that evoke a "sense of heated exaggeration [and] suspiciousness" (Hofstadter 1964, 3). This so-called "paranoid style" often reflects a deep distrust of secret organizations, foreign governments, centralized authority, and those in positions of power in politics, business, and finance.

Since the publication of The Paranoid Style in American Politics in 1964, however, there has been little, if any, follow-up examination of Hofstadter's observations about paranoid thought in American politics. Moreover, there has been virtually no effort by political scientists to produce a

\footnotetext{
${ }^{1}$ Fake news refers to fabricated stories that are verifiably untrue and intentionally designed to mislead.
} 
systematic examination of the linkages between paranoid thought and one's political beliefs and knowledge. In the present era, which is littered with fake news websites and conspiracy theories that can spread rapidly into the public domain over the Internet (see e.g., Sunstein 2009 and Lewandowsky et al. 2012), Hofstadter's investigation into "the politics of the irrational" warrants revisiting.

In this paper, I attempt to do exactly that. Drawing on the work of psychologists Allan Fenigstein and Peter Vanable (1992), this study systematically examines the relationship between paranoid thought and one's ability to separate political facts from fiction. To produce the analysis, I conducted an original survey of more than 800 adults nationwide. The results confirm my expectation that the "paranoid style" plays a significant role in understanding why some Americans are better informed about political issues than others. By extension, it also sheds light on why some Americans may be more susceptible than others to accept fake news stories as true.

These findings have significant implications for democratic theory, which holds that an informed citizenry is necessary for elections and government to function properly (see e.g., Dahl 1956; Achen and Bartels 2016). The reasons for this concern are clear. Democratic theory holds that citizens must make rational choices consistent with their self-interest (Downs 1957). When that process breaks down due to general political ignorance, elections and governance may reflect preferences inconsistent with the wants and needs of the majority (Bartels 1996; Lau, Anderson, and Redlawsk 2008). Moreover, a society rife with poorly informed citizens cannot engage in the type of informed deliberation considered necessary for a healthy democracy (see e.g., Delli Carpini and Keeter 1996). Thus, by examining the theory of the "paranoid style" in today's modern context of fake news, this research offers potentially useful insights into better understanding how and why people come to accept misinformation - a phenomenon with clear implications for the health and future of American democracy, and even for public safety as the recent "Pizzagate" event illustrates. 


\section{The Rise of Fake News and the Antecedents of Belief in Misinformation}

The spread of political propaganda, rumors, and falsehoods dates back to the earliest days of the American republic. In the election of 1800, for example, opponents of Thomas Jefferson spread the claim that his victory would result in "the Bible [being] cast into a bonfire... our wives and daughters [becoming] the victims of legal prostitution” (quoted in Boller 2004, 12). Not to be outdone, Jefferson's supporters planted a story that his opponent, President John Adams, intended to arrange a marriage between one of his sons and one of the daughters of King George III in a plot to reunite the United States and Great Britain (Baumgartner and Francia 2016, 116). In perhaps the most sensational charge of all during the election, Jefferson's camp planted a rumor that President Adams had such a voracious sexual appetite that he ordered his running mate, Charles Pinckney, to bring back four "pretty girls" from England - two for him and two for two Pickney (Boller 2004, 13). Of course, none of these stories were true. Nonetheless, the accusations spread widely enough throughout the country that Adams himself felt compelled to respond to them, remarking of the latter charge, "If this be true, General Pinckney has kept them all for himself and cheated me out of my two" (Swint 2006, 185).

In more recent times, there has been no shortage of misinformation and conspiracy theories on subjects ranging from the assassination of President John F. Kennedy to the moon landing to the terrorist attacks on September 11, 2001 (Uscinski and Parent 2014). Public opinion polls further reveal that a significant percentage of Americans believe in such conspiracies (Stempel, Hargrove, and Stempel 2007; Oliver and Wood 2014, 953). Even on matters concerning current events, a large majority of people who were exposed to fake news during the 2016 presidential election often believed it to be true (Silverman and Singer-Vine 2016), especially when the information contained in these fake news stories favored the recipient's preferred candidate (Allcott and Gentzkow 2017). 
This development is concerning because once these false beliefs take root, research overwhelmingly demonstrates that individuals become highly resistant to correction, even when exposed later to accurate information that overwhelmingly shows the rumor or conspiracy to be fraudulent (see e.g., Nyhan and Reifler 2010; Berinsky 2015; Thorson 2016). Thorson (2016), for example, describes a "belief echo" in which mere exposure to political misinformation continues to influence beliefs, even after the incorrect information has been indisputably discredited. Given the serious implications that the spread of misinformation can have on the health of a democracy (as described earlier) and on the difficulties that exist in correcting it, the present academic literature often focuses on the effectiveness of fact-checkers to correct bad information (see e.g., Fridkin, Kenney, and Wintersieck 2015; Graves 2016; Wintersieck 2017).

My focus in this study, however, is less concerned with the reasons for the stubborn persistency in people to believe false political stories, or in the strategies that work best to correct misinformation. Instead, my goal in this paper, broadly speaking, is to examine the psychological antecedents that explain why some people are more prone than others to accept fake news stories as true. In this area of research, Berinsky (2011) points us towards perhaps the most common-sense explanation: one's political knowledge. That is, people higher in knowledge are less likely to endorse political rumors. Miller, Saunders, and Farhart (2016) further explore the psychological portrait of those most likely to be accepting of political conspiracy theories, finding that conspiracy endorsement tends to be most common among individuals who are actually highly knowledgeable about politics, but lacking in trust.

Related research points to partisanship and ideology by drawing on the theory of what psychologists call “motivated reasoning” (Kunda 1990; Taber and Lodge 2006). A person’s preexisting partisan and ideological preferences effectively become the lens through which an individual perceives new information. In simple terms, a strongly partisan Democrat is motivated to dismiss 
new information that is favorable to Republicans or unfavorable to Democrats, or to accept new information that is favorable to Democrats or unfavorable to Republicans (Bartels 2002). This is especially true of political rumors, with strong partisans and ideologues motivated to believe the worst about their political opponents (DiFonzo and Bordia 2007). The theory of motivated reasoning thereby suggests that fake news stories are more likely to be believed or discounted based on how compatible the story is with one's partisan and ideological outlook, regardless of the objective evidence (Flynn, Nyhan, and Reifler 2017).

Yet, while knowledge, trust, partisanship, and ideology are all undoubtedly a part of the larger process that helps to explain susceptibility to political misinformation, I argue that an additional variable warrants consideration: an individual's level of paranoia. Perhaps the most widely used measure of paranoia in survey research comes from Fenigstein and Vanable (1992). Social scientists have utilized the Fenigstein and Vanable Paranoia Scale (PS) to study relationships between paranoia and numerous behaviors and attitudes. Some examples include paranoia and Machiavellianism (i.e., those predisposed to be conniving and deceptive; Christofferson and Sharp 1995); paranoia and racism (Combs et al. 2006); and paranoia and religious discrimination (Rippy and Newman 2006) to list just a few.

The PS measures nonclinical, nonpathological paranoia that occurs in interpersonal situations. In the words of the authors, "Normal individuals engage in a variety of implausible interpretations or ideational distortions in attempting to explain events....[T] occurrences within the normal population are frequently and casually referred to or described as paranoid' (Fenigstein and Vanable 1992, 130). This description is conceptually similar to Hofstadter's (1964) description of paranoia. Like Fenigstein and Vanable, Hofstadter makes clear that, when referring to paranoia, he is "not speaking in a clinical sense" but rather is referring to "modes of expression by more or less normal people" that are characterized by "delusions of persecution" 
$(1964,3)$. Although perhaps not a perfect match in definitions, there is enough similarity in the descriptions of paranoia for the PS to serve as a reasonable proxy to capture Hofstadter's "paranoid syle."

Using the PS, this paper offers the following contribution to the academic literature: It provides a quantitative twist to Hofstadter's seminal work, and more importantly, offers a first look at the potential linkages between paranoia and one's willingness to accept or deny established political facts. I hypothesize that, even after controlling for other factors previously found in the literature to affect a person's propensity to believe misinformation, those most paranoid will be the most likely and willing to believe incorrect information that became popularized through fake news websites. Indeed, the conspiratorial themes common on many fake news websites seem tailor made for those with more paranoid mindsets.

By understanding why some people accept fake news more than others, we can begin to understand why fake news has taken such hold on significant numbers of Americans. As one study found, Facebook users were more likely to share popular fake news stories than they were popular mainstream news stories (Allcott and Gentzkow 2017). Likewise, a report from the publication, Burzfeed, found that Facebook activity, including likes, comments, and shares, was greater for the most popular fake news stories than for the most popular real news stories (Silverman et al. 2016). With advances in communications technology through the Internet and social media platforms, misinformation now spreads throughout the nation quickly and more easily than ever before, often with significant consequences (Sunstein 2009; Lewandowsky et al. 2012).

Although many of the websites that initially supply fake news exist for only a brief period, once misinformation spreads, it can often become difficult to contain and correct. Indeed, repeating a rumor, even when there is direct refutation of it, can actually make those exposed to it more likely to believe it (Berinsky 2015). Thus, the repetition and spread of fake news through social media 
platforms presents a somewhat graver threat to the informed citizenry that democracy requires than perhaps at any other time in history.

\section{Data and Methods}

The data used for the analysis in this study is based on a general population survey of American adults nationwide that I conducted through the Center for Survey Research at East Carolina University. The survey data were collected over roughly a three-week period from May 26 through June 13, 2017. Respondents completed the survey online. The firm, Survey Sampling International, provided the online sample. To ensure the demographic representativeness of the sample, quotas were put into place that matched the nationwide general population statistics on age, gender, race, and education, as provided by the U.S. Census. Quotas were also put into place for party identification using the most current statistics for 2017 provided by Gallup. In total, there were 879 completed responses. To avoid self-selection bias, the nature of the survey was not divulged to potential participants. To ensure data quality, two validity checks were included in the survey to ensure that respondents were reading the questions carefully before answering them.

Before discussing the measurement of the variables used in the analysis, I wish to acknowledge an additional point about the data: the survey responses in this study did not rely on a probability sample, which might prompt concerns about the generalizability of the results. While there is no disputing that a randomized sample with a healthy response rate produces the most generalizable data, a recent report from the Pew Research Center found that response rates for the typical telephone survey, drawn from a randomized sample, fell from 36 percent in 1997 to just 6 percent in 2018 (Kennedy and Hartig 2019). These exceptionally low response rates raise concerns about nonresponse bias in probability samples. Moreover, with roughly 290 million Internet users in the United States, delivery of online surveys and polls has become increasingly popular and 
accepted, with some research showing that carefully executed opt-in Internet panels, such as the one utilized in this study from Survey Sampling International, can produce results as accurate as those taken from telephone surveys that draw from a probability sample (Ansolabehere and Schaffner 2014).

To measure the variable of primary interest, paranoia, I replicated the measure developed by Fenigstein and Vanable (1992), asking respondents to: "Please rate how applicable each belief is to you by selecting a number between 1 (not at all applicable to me) and 5 (extremely applicable to me)."

1. Someone has it in for me.

2. I sometimes feel as if I'm being followed.

3. I believe that I have often been punished without cause.

4. Some people have tried to steal my ideas and take credit for them.

5. My parents and family find more fault with me than they should.

6. No one really cares much what happens to you.

7. I am sure I get a raw deal from life.

8. Most people will use somewhat unfair means to gain profit or an advantage, rather than lose it.

9. I often wonder what hidden reason another person may have for doing something nice for you.

10. It is safer to trust no one.

11. I have often felt that strangers were looking at me critically.

12. Most people make friends because friends are likely to be useful to them.

13. Someone has been trying to influence my mind.

14. I am sure I have been talked about behind my back. 
15. Most people inwardly dislike putting themselves out to help other people.

16. I tend to be on my guard with people who are somewhat more friendly than I expected.

17. People have said insulting and unkind things about me.

18. People often disappoint me.

19. I am bothered by people outside, in cars, in stores, etc. watching me.

20. I have often found people jealous of my good ideas just because they had not thought of them first.

These 20 items make up the PS scale, with scores that can range from 20 to 100, with higher scores reflective of greater nonclinical paranoia. For this study, the PS scale demonstrated excellent internal consistency (alpha $=.94) .{ }^{2}$ I transform the PS using the natural log function to obtain residuals that are more symmetrically distributed.

To test whether those who are the most paranoid will be the most likely and willing to believe misinformation, the survey instructed the following: "For each of the following statements, please indicate whether the statement is true or false. If you are unsure, please make your best guess." Some of the statements included in the survey are purely factual without any fake news controversy attached to them. Other statements are likewise factual but did contain a fake news controversy. A separate category of statements involves more long-standing political conspiracies. I include these statements as well in the analysis.

\footnotetext{
${ }^{2}$ In constructing the PS, $11 \%$ of the cases in the survey were missing at least one value out of the 20 items. I used the technique of multiple imputation to prevent unnecessarily dropping cases from the analysis due to missing values. Multiple imputation involves replacing missing values with multiple values based off of an observed variable (Lall 2016). This has proven to be an effective technique for replacing missing data in many fields of study, including political science (King et al. 2001; Arel-Bundock and Pelc 2018).
} 
I. Factual Statements (* designates if it included a fake news controversy)

1. 'The stock market's Dow Jones Industrial Average reached an all-time record high while Donald Trump has been president." (The correct answer is true. There is no fake news attached to this claim.)

2. "In the 2016 election, white women were more likely to vote for Donald Trump than for Hillary Clinton." (The correct answer is true. There is no fake news attached to this claim.)

3. "Hillary Clinton received more popular votes than Donald Trump did in the 2016 presidential election."* (The correct answer is true.)

* The fake news website "70news" or 70news.wordpress.com, which redirects viewers to a WordPress blog page, is one example of a "fake news" website that has claimed Trump won the popular vote. (See https://www.cbsnews.com/pictures/dont-get-fooled-by-these-fakenews-sites $/ 2 /$.

4. "Three million people or more voted illegally in the 2016 election."* (The correct answer is false.)

* This incorrect claim was spread via Facebook shortly after the election as well as by InfoWars.com and other dubious sources. (See https://www.snopes.com/fact-check/threemillion-votes-in-presidential-election-cast-by-illegal-aliens. A similar claim ran on YourNewsWire, a Los Angeles-based website that runs aggregated political news mixed in with some fabricated stories.)

II. Conspiracies (for these statements, respondents were instructed to answer "yes" or "no").

5. Thinking about space exploration, do you think the government staged or faked the Apollo moon landing?

6. Do you think the US government is covering up a UFO crash in Roswell, New Mexico?

7. Did President George W. Bush know about the $9 / 11$ terrorist attacks before they happened? 
8. Do you think there is such a thing as a "deep state" (i.e. military, intelligence, and government officials who secretly manipulate government policy) in this country?

\section{Bivariate Results}

I begin with the first statement, which contains no fake news controversy: "The stock market's Dow Jones Industrial Average reached an all-time record high while Donald Trump has been president." Those who answered correctly (true) were coded 1. Those who answered incorrectly (false) were coded 0 . Because the dependent variable is binary, I use estimates generated from logistic regression. As the results show below in Table 1, paranoia does not reach statistical significance. The results are similar in Table 2. Paranoia again fails to reach statistical significance when analyzing its relationship to the second statement, "In the 2016 election, white women were more likely to vote for Donald Trump than for Hillary Clinton.” Although paranoia is insignificant, both results are not unexpected given that there was no fake news generated around either of these two statements.

Table 1. The Relationship Between Paranoia and Correctly Answering that the Stock Market Reached an All-Time High While Trump Has Been President

\begin{tabular}{rr|r|r|r|r|r} 
& & & & & \\
& B & \multicolumn{1}{c}{ S.E. } & Wald & df & \multicolumn{1}{c|}{ Sig. } & \multicolumn{1}{c|}{ Exp(B) } \\
\hline Log_Paranoia & -.668 & .433 & 2.383 & 1 & .123 & .513 \\
\hline Constant & 1.802 & .702 & 6.593 & 1 & .010 & 6.061 \\
\hline
\end{tabular}

$N=849$

Table 2. The Relationship Between Paranoia and Correctly Answering that White Women Were More Likely to Vote for Donald Trump

\begin{tabular}{ll|r|r|r|r|r} 
& \multicolumn{1}{c|}{ B } & \multicolumn{1}{c|}{ S.E. } & \multicolumn{1}{c|}{ Wald } & df & \multicolumn{1}{c}{ Sig. } & Exp(B) \\
\hline Log_Paranoia & .133 & .404 & .109 & 1 & .741 & 1.143 \\
\hline Constant & -.103 & .653 & .025 & 1 & .875 & .902 \\
\hline
\end{tabular}

$N=854$ 
However, when examining the relationship between paranoia and factual statements that were muddied by fake news claims, the results are completely different. Here there is strong statistical significance for paranoia and in the hypothesized direction. Put another way, those who are highest on the paranoia continuum (score highest on the PS) are the most likely to answer incorrectly on factual statements that fake news websites cover and discuss.

Table 3. The Relationship Between Paranoia and Correctly Answering that Clinton Received More Popular Votes than Trump in the 2016 Presidential Election

\begin{tabular}{ll|r|r|r|r|r} 
& \multicolumn{1}{l|}{ B } & \multicolumn{1}{l|}{ S.E. } & \multicolumn{1}{c}{ Wald } & df & \multicolumn{1}{c}{ Sig. } & \multicolumn{1}{c}{$\operatorname{Exp}(\mathrm{B})$} \\
\hline Log_Paranoia & -2.074 & .535 & 15.014 & 1 & .000 & .126 \\
\hline Constant & 4.869 & .883 & 30.384 & 1 & .000 & 130.231 \\
\hline
\end{tabular}

$N=854$

Table 4. The Relationship Between Paranoia and Correctly Rejecting the Statement that Three Million People or More Voted Illegally in the 2016 election

\begin{tabular}{rlr|r|r|r|r|r} 
& & \multicolumn{1}{c}{ B } & S.E. & Wald & df & Sig. & Exp(B) \\
\hline Step $1^{\mathrm{a}}$ & Log_Paranoia & -1.387 & .433 & 10.246 & 1 & .001 & .250 \\
\cline { 2 - 8 } & Constant & 2.879 & .705 & 16.692 & 1 & .000 & 17.801 \\
\hline
\end{tabular}

$N=852$

In addition, the results suggest that paranoia is strongly related to acceptance of popular political conspiracies (see Tables 5-8). This is likewise consistent with earlier expectations.

Table 5. The Relationship Between Paranoia and Belief that the Government Staged or Faked the Apollo Moon Landing

\begin{tabular}{|c|c|c|c|c|c|c|c|}
\hline & & $\mathrm{B}$ & S.E. & Wald & Df & Sig. & $\operatorname{Exp}(B)$ \\
\hline \multirow[t]{2}{*}{ Step $1^{\mathrm{a}}$} & Log_Paranoia & 4.810 & .677 & 50.458 & 1 & .000 & 122.787 \\
\hline & Constant & -9.833 & 1.154 & 72.611 & 1 & .000 & .000 \\
\hline
\end{tabular}

$\mathrm{N}=857$ 
Table 6. The Relationship Between Paranoia and Belief that the US Government is Covering Up a UFO Crash in Roswell, New Mexico

\begin{tabular}{ll|r|r|r|r|r} 
& B & S.E. & Wald & Df & Sig. & Exp(B) \\
\hline Log_Paranoia & 2.226 & .421 & 27.947 & 1 & .000 & 9.267 \\
\hline Constant & -3.766 & .682 & 30.502 & 1 & .000 & .023 \\
\hline
\end{tabular}

$N=855$

Table 7. The Relationship Between Paranoia and Belief that President George W. Bush Knew about the 9/11 Terrorist Attacks Before They Happened

\begin{tabular}{ll|r|r|r|r|r} 
& B & S.E. & Wald & Df & Sig. & Exp(B) \\
\hline Log_Paranoia & 3.516 & .486 & 52.347 & 1 & .000 & 33.637 \\
\hline Constant & -6.629 & .803 & 68.084 & 1 & .000 & .001 \\
\hline
\end{tabular}

$N=857$

Table 8. The Relationship Between Paranoia and Belief in the Deep State

\begin{tabular}{|c|c|c|c|c|c|c|c|}
\hline & & $\mathrm{B}$ & S.E. & Wald & Df & Sig. & $\operatorname{Exp}(B)$ \\
\hline \multirow[t]{2}{*}{ Step $1^{a}$} & Log_Paranoia & 2.455 & .438 & 31.433 & 1 & .000 & 11.652 \\
\hline & Constant & -3.410 & .700 & 23.753 & 1 & .000 & .033 \\
\hline
\end{tabular}

$N=854$

\section{Multivariate Results}

The next section explores the results further using multivariate analysis. Because the bivariate results confirmed no relationship between paranoia on the first two statements unrelated to fake news (i.e, the stock mark reaching an all-time high under Donald Trump and the fact that white women were more likely to vote for Trump than for Clinton), the multivariate analysis presented in Tables 9 and 10 does not include them. That leaves six items, two of which involved fake news coverage and four of which involved conspiracies. These six survey questions each serve as a 
dependent variable in six separate logistic regression equations. The two involving fake news are presented in Table 9. The four involving conspiracies are presented in Table 10. All six items are binary variables (coded 0 or 1 ) as described and defined in the previous section.

The explanatory variable of interest remains the paranoia scale (PS). (See above for an explanation of how it was created and coded.) The controls that have been added to the analysis in Tables 9 and 10 include factors cited in the literature, such as trust ${ }^{3}$, strong partisanship ${ }^{4}$, and ideology ${ }^{5}$ shown to influence one's susceptibility to believing fake news or belief in conspiracy. Additional socio-economic factors such as age ${ }^{6}$, race $^{7}$, gender $^{8}$, and education ${ }^{9}$ serve as standard control variables in the models.

The results in both equations in Table 9 reveal that paranoia remains statistically significant, even after controlling for various factors. Individuals who score higher on the paranoia continuum are less likely to provide correct answers to true-false questions about which presidential candidate won the popular vote in 2016 and about illegal voting activity during the 2016 election. The results are similar in Table 10. Even with controls, there is a strong and statistically significant relationship between an individual's level of paranoia and his or her susceptibility to believing conspiracy theories.

\footnotetext{
3 Trust is based on responses to two questions in the survey: How often can you trust the federal government in Washington to do what is right? Generally speaking, how often can you trust other people? For both questions, response categories were: (1) Never, (2) Some of the time, (3) About half the time, (4) Most of the time, (5) Always. Responses to the two questions were added together, creating a trust scale that ranged from 2 to 10.

${ }^{4}$ Strong partisanship is based on the standard set of ANES party identification questions; see https://electionstudies.org/resources/anes-guide. Those who identified as "strong" Democrats are coded as 1; others as 0. In a separate variable, those who identified as "strong" Republicans are coded 1; others 0.

${ }^{5}$ Ideology is based on answers to the question: In general, how would you describe your political views? The measure is coded as: (1) Very liberal, (2) Liberal, (3) Slightly liberal, (4) Moderate or middle of the road, (5) Slightly conservative, (6) Conservative, and (7) Very Conservative.

${ }^{6}$ Age is coded in years from the time that the survey was taken in 2017.

${ }^{7}$ Race is collapsed into a binary variable in which white respondents are coded 1 and non-whites are coded 0.

${ }^{8}$ Gender is coded as 1 for female and 0 for male.

${ }^{9}$ Education is coded as follows: (1) Less than high school, (2) High school graduate or GED, (3) Some college or an Associate degree, (4) Bachelor's degree, and (5) Post-graduate degree.
} 
Table 9. Logistic Regression Estimates for Answering Accurately on Issues Covered by Fake News Websites

\begin{tabular}{|c|c|c|}
\hline Paranoia (PS log) & $\begin{array}{c}\text { Popular Vote Winner } \\
-1.431^{*} \\
(.660)\end{array}$ & $\begin{array}{c}\text { Illegal Voting } \\
-1.345^{\star \star} \\
(.537)\end{array}$ \\
\hline Trust scale & $\begin{array}{l}.027 \\
(.069)\end{array}$ & $\begin{array}{l}.221^{\star \star \star} \\
(.059)\end{array}$ \\
\hline Ideology (conservative) & $\begin{array}{l}-.246^{\star * *} \\
(.077)\end{array}$ & $\begin{array}{l}-.434^{\star * *} \\
(.063)\end{array}$ \\
\hline Strong Republican & $\begin{array}{l}.312 \\
(.288)\end{array}$ & $\begin{array}{l}-.354 \\
(.232)\end{array}$ \\
\hline Strong Democrat & $\begin{array}{l}1.080 * \star \star \\
(.390)\end{array}$ & $\begin{array}{r}.068 \\
(.257)\end{array}$ \\
\hline Age & $\begin{array}{l}.017^{\star *} \\
(.007)\end{array}$ & $\begin{array}{c}.002 \\
(.005)\end{array}$ \\
\hline White & $\begin{array}{l}-.342 \\
(.244)\end{array}$ & $\begin{array}{l}-.041 \\
(.194)\end{array}$ \\
\hline Female & $\begin{array}{l}-.591^{\star \star} \\
(.210)\end{array}$ & $\begin{array}{l}.155 \\
(.170)\end{array}$ \\
\hline Education & $\begin{array}{l}.383^{\star \star \star} \\
(.098)\end{array}$ & $\begin{array}{c}.066 \\
(.074)\end{array}$ \\
\hline Constant & $\begin{array}{c}3.432 \\
(1.365)\end{array}$ & $\begin{array}{c}3.424 \\
(1.102)\end{array}$ \\
\hline $\begin{array}{l}\mathrm{N} \\
\text { Nagelkerke } \mathrm{R}^{2}\end{array}$ & $\begin{array}{l}781 \\
.164\end{array}$ & $\begin{array}{l}778 \\
.206\end{array}$ \\
\hline
\end{tabular}

${ }^{*} \mathrm{p}<.05,{ }^{* \star} \mathrm{p}<.01,{ }^{* * *} \mathrm{p}<.001$. Standard errors are in parentheses. 
Table 10. Logistic Regression Estimates for Belief in Political Conspiracies

\begin{tabular}{|c|c|c|c|c|}
\hline & Moon Landing & Roswell & 9/11 & Deep State \\
\hline Paranoia (PS log) & $\begin{array}{l}3.507^{\star \star \star *} \\
(.762)\end{array}$ & $\begin{array}{l}2.048^{\star \star \star} \\
(.490)\end{array}$ & $\begin{array}{l}2.173^{\star \star \star *} \\
(.552)\end{array}$ & $\begin{array}{l}1.934^{\star \star \star} \\
(.510)\end{array}$ \\
\hline Trust scale & $\begin{array}{l}.089 \\
(.075)\end{array}$ & $\begin{array}{l}-.086 \\
(.053)\end{array}$ & $\begin{array}{l}-.174^{\star \star} \\
(.060)\end{array}$ & $\begin{array}{r}-.158^{\star \star} \\
(.056)\end{array}$ \\
\hline Ideology (conservative) & $\begin{array}{l}.093 \\
(.078)\end{array}$ & $\begin{array}{l}.031 \\
(.054)\end{array}$ & $\begin{array}{l}.042 \\
(.059)\end{array}$ & $\begin{array}{l}.148^{\star \star} \\
(.057)\end{array}$ \\
\hline Strong Republican & $\begin{array}{l}-.076 \\
(.347)\end{array}$ & $\begin{array}{l}.100 \\
(.225)\end{array}$ & $\begin{array}{l}-.202 \\
(.267)\end{array}$ & $\begin{array}{l}-.226 \\
(.236)\end{array}$ \\
\hline Strong Democrat & $\begin{array}{l}.583 \\
(.318)\end{array}$ & $\begin{array}{l}-.046 \\
(.216)\end{array}$ & $\begin{array}{l}.524^{*} \\
(.234)\end{array}$ & $\begin{array}{l}-.154 \\
(.223)\end{array}$ \\
\hline Age & $\begin{array}{l}-.025^{\star *} \\
(.008)\end{array}$ & $\begin{array}{l}-.003 \\
(.005)\end{array}$ & $\begin{array}{l}-.023^{\star \star \star} \\
(.006)\end{array}$ & $\begin{array}{l}-.019 * \star \star \\
(.005)\end{array}$ \\
\hline White & $\begin{array}{l}.237 \\
(.273)\end{array}$ & $\begin{array}{l}-.273 \\
(.175)\end{array}$ & $\begin{array}{l}-.316 \\
(.193)\end{array}$ & $\begin{array}{l}.106 \\
(.182)\end{array}$ \\
\hline Female & $\begin{array}{l}.029 \\
(.240)\end{array}$ & $\begin{array}{l}.114 \\
(.156)\end{array}$ & $\begin{array}{l}-.079 \\
(.177)\end{array}$ & $\begin{array}{l}.396^{*} \\
(.162)\end{array}$ \\
\hline Education & $\begin{array}{l}-.193 \\
(.107)\end{array}$ & $\begin{array}{l}-.317^{\star \star \star} \\
(.069)\end{array}$ & $\begin{array}{l}-.074 \\
(.078)\end{array}$ & $\begin{array}{l}-.015 \\
(.071)\end{array}$ \\
\hline Constant & $\begin{array}{c}7.239 \\
(1.536)\end{array}$ & $\begin{array}{r}-2.034 \\
(.992)\end{array}$ & $\begin{array}{c}2.407 \\
(1.117)\end{array}$ & $\begin{array}{l}-1.577 \\
(1.034)\end{array}$ \\
\hline $\begin{array}{l}\mathrm{N} \\
\text { Nagelkerke } \mathrm{R}^{2}\end{array}$ & $\begin{array}{l}783 \\
.140\end{array}$ & $\begin{array}{l}781 \\
.108\end{array}$ & $\begin{array}{l}783 \\
.146\end{array}$ & $\begin{array}{l}780 \\
.110\end{array}$ \\
\hline
\end{tabular}

${ }^{*} p<.05,{ }^{* *} p<.01,{ }^{* *} p<.001$. Standard errors are in parentheses. 


\section{Conclusion}

The results in this study suggest that the so-called "paranoid style" - a term coined more a half-century ago - is a concept worthy of re-visiting in American politics, particularly in the current age of fake news. Although the author of that term, Richard Hofstadter, was a historian, and he applied the term through traditional historical research, psychologists have also examined similar, nonclinical descriptions of paranoia and its effects in a variety of different contexts. Of note, the psychologists Fenigstein and Vanable developed a measurable scale of nonclinical paranoia that other scholars have used widely in their research to study the effects of paranoia on behavior and attitudes.

Drawing conceptually from Hofstadter and using the measure of paranoia developed by Fenigstein and Vanable, this paper examined whether individuals with higher levels of paranoid thought, occurring in everyday interpersonal situations, are more likely to struggle to find correct answers to factual-based political questions in an environment where fake news sources and social media platforms can easily disseminate incorrect information. The analysis in this paper revealed results that suggest such a relationship does indeed exist. Two important and related points from the analysis stand out: (1) Paranoia showed no relationship to a person's ability to answer factual-based political questions on items that fake news sources did not cover or address. (2) But, when fake news sources did weigh in on a political knowledge question asked in the survey, the measure for paranoia, as it increased, showed significant effects in a negative direction on a person's ability to answer correctly. This relationship also existed on items that addressed commonly discussed conspiracies about politics and government - conspiracies that often find voice as well on websites and through social media platforms.

As fake news continues to proliferate in U.S. elections and politics, increasing volumes of misinformation becomes an ever-greater danger to American democracy. The public's ability to 
decipher fact from fiction is at risk, and as the results in this study show, this is most true for those predisposed to a paranoid mindset. As James Madison once warned, "A popular Government, without popular information, or the means of acquiring it, is but a Prologue to a Farce or a Tragedy; or, perhaps both" (quoted in Lupia and McCubbins 1998, 1). 


\section{References}

Achen, Christopher H., and Larry M. Bartels. 2016. Democracy for Realists: Why Elections do not Produce Responsive Government. Princeton, NJ: Princeton University Press.

Allcott, Hunt, and Matthew Gentzkow. 2017. "Social Media and Fake News in the 2016 Election." The Journal of Economic Perspectives 31(2): 211-235.

Ansolabehere, Stephen, and Brian F. Schaffner. 2014. “Does Survey Mode Still Matter? Findings from a 2010 Multi-Mode Comparison.” Political Analysis 22(3): 285-303.

Arel-Bundock, Vincent, and Krzysztof J. Pelc. 2018. "When Can Multiple Imputation Improve Regression Estimates?” Political Analysis 26(2): 240-245.

Bartels, Larry M. 1996. “Uninformed Votes: Information Effects in Presidential Elections.” American Journal of Political Science 40:194-230.

Bartels, Larry M. 2002. "Beyond the Running Tally: Partisan Bias in Political Perceptions.” Political Behavior 24(2): 117-150.

Baumgartner, Jody C., and Peter L. Francia. 2016. Conventional Wisdom and American Elections: Exploding Myths, Exploring Misconceptions. New York: Rowman \& Littlefield.

Berinsky, Adam J. 2011. "Rumors, Truth, and Reality: A Study of Political Misinformation."

Presented at the Annual Meeting of the Midwest Political Science Association, Chicago.

Berinsky, Adam J. 2015. "Rumors and Health Care Reform: Experiments in Political Misinformation.” British Journal of Political Science 47(2): 241-262.

Boller, Paul F., Jr. 2004. Presidential Campaigns: From George W ashington to George W. Bush. New York: Oxford University Press.

Carpini, Michael X. Delli, and Scott Keeter. 1996. What Americans Know About Politics and Why it Matters. New York: Yale University Press. 
Christoffersen, David, and Clifton Stamp. 1995. "Examining the Relationship Between Machiavellianism and Paranoia." Psychological Reports 76(1): 67-70.

Combs, Dennis R., David L. Penn, Jeffrey Cassisi, Chris Michael, Terry Wood, Jill Wanner, and Scott Adams. "Perceived Racism as a Predictor of Paranoia Among African Americans." 2006. Journal of Black Psychology 32(1): 87-104.

Dahl, Robert A. 1956. A Preface to Democratic Theory. Chicago: University of Chicago Press.

DiFonzo, Nicholas, and Prashant Bordia. 2007. Rumor Psychology: Social and Organizational Approaches. Washington, DC: American Psychological Association.

Downs, Anthony. 1957. An Economic Theory of Democracy. New York: Harper \& Row.

Flynn, D.J., Brendan Nyhan, and Jason Reifler. 2017. “The Nature and Origins of Misperceptions: Understanding False and Unsupported Beliefs About Politics.” Political Psychology 38(S1): $127-$ 150.

Fridkin, Kim, Patrick J. Kenney, and Amanda Wintersieck. 2015. “Liar, Liar, Pants on Fire: How Fact-Checking Influences Citizens’ Reactions to Negative Advertising." Political Communication 32(1): 127-151.

Graves, Lucas. 2016. Deciding What's True: The Rise of Political Fact-Checking in American Journalism. New York: Columbia University Press.

Hofstadter, Richard. 1964. The Paranoid Style in American Politics. New York: Knopf.

Kennedy, Courtney, and Hannah Hartig. 2019. "Response Rates in Telephone Surveys Have Resumed Their Decline.” Pew Research Center, February 27, 2019, https://www.pewresearch.org/fact-tank/2019/02/27/response-rates-in-telephone-surveyshave-resumed-their-decline. 
King, Gary, James Honaker, Anne Joseph, and Kenneth Scheve. 2001. “Analyzing Incomplete Political Science Aata: An Alternative Algorithm for Multiple Imputation.” American Political Science Review 95(1): 49-69.

Korte, Gregory. 2016. “Fake News Threatens Democracy, Obama Says.” USA Today, November 17, https://www.usatoday.com/story/tech/2016/11/17/fake-news-threatens-democracyobama-says/94045428.

Kunda, Ziva. 1990. “The Case for Motivated Reasoning.” Psychological Bulletin 8(3): 480-498.

Lall, Ranjit. 2016. "How Multiple Imputation Makes a Difference.” Political Analysis 24(4): 414-433.

Lau, Richard R., David J. Andersen, and David P. Redlawsk. 2008. “An Exploration of Correct Voting in Recent US Presidential Elections." American Journal of Political Science 52: 395-411.

Lewandowsky, Stephan, Ullrich K.H. Ecker, Colleen M. Seifert, Norbert Schwarz, and John Cook. 2012. "Misinformation and Its Correction: Continued Influence and Successful Debiasing." Psychological Science in the Public Interest 13(3): 106-131.

Lupia, Arthur, and Mathew D. McCubbins. 1998. The Democratic Dilemma: Can Citizens Learn What They Need to Know? Cambridge, MA: Cambridge University Press.

Miller, Joanne M., Kyle L. Saunders, and Christina E. Farhart. 2016. “Conspiracy Endorsement as Motivated Reasoning: The Moderating Roles of Political Knowledge and Trust." American Journal of Political Science 60(4): 824-844.

Nyhan, Brendan, and Jason Reifler. 2010. "When Corrections Fail: The Persistence of Political Misperceptions." Political Behavior 32(2): 303-330.

Oliver, J. Eric, and Thomas J. Wood. 2014. "Conspiracy Theories and the Paranoid Style(s) of Mass Opinion.” American Journal of Political Science 58(4): 952-966. 
Rippy, Alyssa E., and Elana Newman. 2006. "Perceived Religious Discrimination and Its Relationship to Anxiety and Paranoia Among Muslim Americans." Journal of Muslim Mental Health 1(1): 520.

Silverman, Craig, Lauren Strapagiel, Hamza Shaban, Ellie Hall, and Jeremy Singer-Vine. 2016. "Hyperpartisan Facebook Pages Are Publishing False and Misleading Information at an Alarming Rate.” BuzzFeedNews, October 20. https://www.buzzfeed.com/craigsilverman/partisan-fb-pages-analysis

Stempel, Carl, Thomas Hargrove, and Guido H. Stempel, III. 2007. "Media Use, Social Structure, and Belief in 9/11 Conspiracy Theories.” Journalism \& Mass Communication Quarterly 84(2): 353-372.

Sunstein, Cass R. 2009. On Rumors: How Falsehoods Spread, Why We Believe Them, What Can Be Done. New York: Farrar, Straus and Giroux.

Swint, Kerwin C. 2006. Mudslingers: The Top 25 Negative Political Campaigns of All Time. Westport, CT: Praeger.

Taber, Charles S., and Milton Lodge. 2006. "Motivated Skepticism in the Evaluation of Political Beliefs." American Journal of Political Science 50(3): 755-769.

Thorson, Emily. 2016. "Belief Echoes: The Persistent Effects of Corrected Misinformation.” Political Communication 33(3): 460-490.

Uscinski, Joseph E., and Joseph M. Parent. 2014. American Conspiracy Theories. New York: Oxford University Press.

Wintersieck, Amanda L. 2017. "Debating the Truth: The Impact of Fact-Checking During Electoral Debates.” American Politics Research 45(2): 304-331. 